\title{
Mejoras del proceso endoscópico usando aplicaciones móviles
}

\author{
Miguel A. Razo Salas ${ }^{1}$, Sodel Vázquez Reyes ${ }^{1}$, Roberto Solís Robles ${ }^{1}$ \\ mikesalas21@gmail.com, vazquezs@uaz.edu.mx, rsolis@uaz.edu.mx \\ ${ }^{1}$ Unidad Académica de Ingeniería Eléctrica-Universidad Autónoma de Zacatecas, 980oo, Zacatecas, México.
}

DOI: 10.17013/risti.17.115-127

\begin{abstract}
Resumen: La endoscopia es un proceso utilizado para realizar operaciones quirúrgicas donde se introduce al cuerpo humano una cámara de video (endoscopio) transmitiendo así imágenes y video a una pantalla. En la actualidad el Hospital General de Zacatecas, al no contar con el equipo médico adecuado, se utiliza un endoscopio genérico conectado mediante el puerto USB a una computadora portátil y así realizar los procedimientos quirúrgicos. Sin embargo, es conveniente sustituir la computadora portátil utilizando un dispositivo móvil para mostrar las imágenes captadas, capturarlas y grabar video con el endoscopio genérico, facilitando la toma de decisiones a los doctores durante las operaciones quirúrgicas. El artículo muestra el proceso que se ha estado siguiendo para mejorar el procedimiento y darle otra opción a los doctores para resolver la problemática. Asimismo, se describen 30 pruebas reales de 14 diferentes procedimientos quirúrgicos, donde los resultados determinan que la solución propuesta es viable, ya que permite una mayor agilidad en el proceso y en la toma de decisiones.
\end{abstract}

Palabras-clave: endoscopía, software, proceso, Dashcam, endoscopio.

\section{Endoscopic process improvement using mobile applications}

\begin{abstract}
Endoscopy is a process used to make surgical operations where a video camera is introduced to a human body (endoscope) and transmits images and video to the screen. Currently, due to a lack of adequate medical equipment, the General Hospital of Zacatecas uses a generic endoscope connected through an USB port to a laptop, which helps perform surgical procedures. Nevertheless, it is convenient to replace the laptop with a mobile device to show the images taken with the generic endoscope, save them and record video, facilitating the decision-making process to the doctors during the surgical operations. This article shows the process that they have been following, in order to improve the procedure and give the doctors a second choice to resolve the issue. Furthermore, it describes 30 actual tests of 14 different surgical procedures, where the results determine that the solution given is viable, as it allows a better agility in the process and in the decision-making.
\end{abstract}

Keywords: endoscopy, software, process, Dashcam, endoscope. 


\section{Introducción}

El uso y manejo de dispositivos móviles en la práctica médica apoyado con la aplicación y desarrollo de software especializado, constituyen una de las opciones que permiten agilizar el trabajo que se realiza en esta área, pues permite la administración de información y tiempo, registro de la salud y acceso, comunicación y consultas, referencias y obtención de información, administración y monitoreo del paciente, la toma de decisiones clínicas, la educación y entrenamiento médico, etc. (Ventola, 2014). En el caso de la endoscopia, el móvil y el software de asistencia médica han constituido una alternativa viable y práctica, pues permiten agilizar el diagnóstico médico y por tanto la toma de decisiones en el tratamiento de los pacientes.

En la actualidad, muchos de los logros y avances médicos son en parte consecuencia a los adelantos tecnológicos, los cuales hacen que el trabajo sea cada vez más rápido y sencillo de realizar, tal es el caso de la endoscopia. El incorporar los endoscopios al mercado ha sido un salto grande en el ámbito de la medicina ya que permite realizar operaciones con mayor precisión dentro del cuerpo humano sin la necesidad de realizar incisiones muy grandes en el paciente para poder llegar a visualizar los órganos internos. La endoscopia es una técnica que se usa para diagnosticar y realizar operaciones quirúrgicas donde se hace uso de una cámara de video especial llamada endoscopio, compuesto por un tubo de fibra óptica largo, flexible y en ocasiones con movilidad, que al introducirlo a través de un orificio natural, una incisión quirúrgica o una lesión transmite imágenes a una pantalla del interior del cuerpo humano, en dependencia del diagnóstico del paciente, y con base a las imágenes transmitidas, el doctor tiene la posibilidad de realizar un procedimiento quirúrgico con mayor exactitud. Normalmente este proceso se lleva a cabo con endoscopios profesionales en donde todos y cada uno de los componentes necesarios para realizar la endoscopia, ya están conectados y listos para usar, sin embargo, se tiene la alternativa de utilizar un endoscopio genérico (cámara web con un diseño y forma de endoscopio para simplificar la inserción al cuerpo humano) con salida de tipo USB para transmitir las imágenes, dando así una mayor flexibilidad y practicidad en la realización del proceso endoscópico.

Las tecnologías de información ha sido utilizadas en varios campos médicos, por ejemplo: un dispositivo BCI comercial, el Emotiv EPOC, para la adquisición de señales en una aplicación con detección inteligente de patrones neuronales en el posible tratamiento del dolor del miembro fantasma en pacientes amputados (Arango, Mazo, \& Palacio, 2013); y para la gestión de la calidad, que ocupa un lugar estratégico en los hospitales, haciendo uso de herramientas informáticas en la arquitectura de la información con el objetivo de responder rápidamente a los cambios en las necesidades y requerimientos de los clientes (Freixo \& Rocha, 2014).

\section{Proceso y Necesidades}

En tiempos recientes el Hospital General de Zacatecas no ha utilizado endoscopios profesionales por ser herramientas sumamente costosas, es por esto que ha estado realizando el proceso endoscópico de diferente manera a la cotidiana en base al endoscopio genérico mencionado en la introducción, el cual reúne y cumple con las exigencias médicas necesarias para realizar los procesos quirúrgicos y provee la mayoría de las funciones que los profesionales, véase tabla 1. 


\begin{tabular}{lccc}
\hline Endoscopio & Genérico & EG-299oi & GIF-XP15oN \\
\hline Marca & N/A & Pentax & Olympus \\
\hline A prueba de Agua & $\checkmark$ & $\checkmark$ & $\square$ \\
\hline Cámara HD & Excelente calidad & $\checkmark$ & Excelente calidad \\
\hline Iluminación & $\checkmark$ & $\checkmark$ & $\checkmark$ \\
\hline Captura de Video & $\checkmark$ & $\checkmark$ & $\checkmark$ \\
\hline Captura de Foto & $\checkmark$ & $\checkmark$ & $\checkmark$ \\
\hline Tamaño del cable & $200 \mathrm{~cm}$ & $105 \mathrm{~cm}$ & $110 \mathrm{~cm}$ \\
\hline Diámetro de cámara & $7 \mathrm{~mm}$ & $9.8 \mathrm{~mm}$ & $5.5 \mathrm{~mm}$ \\
\hline Resistente a temperaturas & Mayor a $80^{\circ}$ & No info. & No info. \\
\hline Movilidad de cámara & $\times$ & $210 / 210$ arriba/abajo, & $210 / 90$ arriba/abajo, \\
\hline Canal de Trabajo & $\times$ & $\checkmark$ & $100 / 100$ izq/derecha \\
\hline
\end{tabular}

Tabla 1 - Especificación y comparación entre diferentes endoscopios ("Endoscopes: Upper Gastrointestinal (GI), Gastroscopy, EG-2990i," 2014),(“Olympus América de México S.A. de C.V.," 2014).

Con un valor menor a \$500.00 MX este endoscopio genérico contiene un CD con su software o driver para utilizarlo, y visualizar las imágenes transmitidas en una computadora conectándolos vía USB, lo cual por su practicidad y bajo costo, se utilizó para resolver los mismos problemas que un endoscopio profesional. Básicamente, el proceso que se sigue para realizar las operaciones quirúrgicas consta del primer paso que es conectar el endoscopio a la computadora portátil vía USB, después ejecutar el driver contenido en el CD para que la computadora se comunique con el endoscopio y pueda capturar imágenes y videos, una vez ya conectado el endoscopio a la computadora con el software funcionando es momento de que el doctor intube a su paciente para diagnosticar alguna enfermedad o realizar algún procedimiento quirúrgico, para esto, se fija el endoscopio al tubo por el cual el doctor meterá los instrumentos para posteriormente introducirlos juntos al interior del cuerpo humano, a causa de que el endoscopio genérico no tiene movilidad propia, es necesario que otro lo guie para que así este trasmita las imágenes del lugar donde el paciente tiene el problema. Una vez el paciente intubado, el doctor introduce sus herramientas de trabajo por el tubo y en base a las imágenes que son captadas por el endoscopio genérico puede tomar decisiones.

Esta herramienta da un alto grado de movilidad y acerca la posibilidad de que lugares con pocos recursos económicos tengan acceso a tecnología importante y necesaria para la salud de las personas y así los médicos brinden un servicio de mayor calidad y sin tantos riesgos. Para esto es obligatorio que el doctor lleve consigo una computadora portátil en caso de alguna emergencia porque de lo contrario no se podría realizar este proceso, lo cual le resta movilidad al proceso en sí y se tiene la posibilidad de que el doctor olvide la computadora por accidente. Por lo anterior, se busca mejorar aún más la movilidad que ya se logró con la PC y acortar los gastos, para así dar una solución con mayor grado de utilidad. 


\section{Solución y Cambio}

Con la necesidad de optimizar aún más el proceso endoscópico se planteó una forma nueva de realizarlo, el proceso es muy similar y el concepto es el mismo. Para el procedimiento se necesita un cable OTG para conectar la salida USB del endoscopio a la entrada del celular, para visualizar las imágenes que el endoscopio transmita pero cambiando la computadora como herramienta básica, por un dispositivo móvil que trabaje bajo un sistema operativo Android, dando así un mayor grado de movilidad o portabilidad ya que el celular como herramienta día a día se ha ido convirtiendo en parte de la vida diaria de las personas. Según IAB México y la firma de investigación Millward Brown, hay 95.5 millones de líneas telefónicas celulares, que es equivalente a que un 85\% de los mexicanos tiene un dispositivo móvil, de los cuales, el 17\% es Smartphone (IAB Mexico, 2012), es decir alrededor de 16.235 millones de personas.

Se inició con la búsqueda de información para ver si era factible realizar una aplicación completamente nueva y desarrollarla desde sus inicios, entonces se accedió a la API de Android para verificar como es que se logaría la conexión entre el endoscopio y el dispositivo móvil, y se encontraron 7 clases para ello: UsbManager, UsbDevice, UsbInterface, UsbEndPoint, UsbDeviceConnection, UsbRequest y UsbConstants, las cuales permitirían la comunicación. Estas clases funcionan de manera que una vez que se inserta un dispositivo USB externo al móvil éste emite una notificación al usuario de tal evento. Ya conectado el dispositivo USB, es necesario identificarlo y esto se logra de una manera sencilla, ya que todos y cada uno de los dispositivos USB están divididos por categorías denominadas: class, subclass, protocol, id_vendor y id_product; cada una de ellas permite tener un identificador más específico para cada dispositivo y así trabajar con el adecuado. Naturalmente estas clases solo proveen métodos para la conexión y no para el manejo del endoscopio, es decir, no hay una API externa que nos indicara la manera de cómo controlar las funciones del endoscopio y existe poca información del mismo. Por consiguiente se tomó la decisión de buscar si ya existía código o aplicaciones que dieran solución a la problemática, dentro de ellas se descubrió una librería open source llamada android-webcam-library la cual dentro de sus características funcionales provee el control de cámaras web con soporte UVC (USB Video Class, clase que distingue a los dispositivos capaces de hacer streaming de vídeo), esta librería consta de dos partes fundamentales: 1) el servicio donde da el funcionamiento principal se ejecuta en segundo plano, y 2) la actividad en sí que hace uso de este servicio, ahora solo era cuestión de hacer funcionar el endoscopio genérico en conjunto con la librería que se acabó de mencionar. Para empezar se inició con una prueba rápida instalando la librería en un dispositivo real, para poder determinar si en realidad funcionaba con resultados no favorables porque la aplicación se cerraba a los pocos segundos de ejecutarse sin mostrar nada en pantalla, esto a causa de que el kernel de los dispositivos Android más recientes cuentan con una clase llamada v4l2 para el streaming de video en lugar de la clase UVC requerida (Christopher Peplin, 2011), llegando a la conclusión de tomar otra alternativa donde el problema no fuera tan especifico.

Dentro de las alternativas encontradas estaban tres aplicaciones en Play Store que según su descripción sirven para capturar fotografías y grabar videos desde una cámara USB 
conectada a un dispositivo inteligente, 1)USBCamera, 2)SnapExWebcam y 3)Dashcam se realizaron pruebas con las tres aplicaciones anteriormente mencionadas, al instalar el USB Camera se conectó el endoscopio al dispositivo móvil y se ejecutó la aplicación, pero no transmitió imágenes y se cerraba por razones desconocidas, ya que el puerto USB por el cual se pudiera hacer una depuración de la aplicación para verificar el error arrojado por la falla estaba ocupado por la conexión de la cámara web; una vez obtenido este resultado poco favorable se procedió a instalar SnapExWebCam teniendo el mismo resultado anterior. Sin embargo ya como última opción quedo instalar y probar Dashcam y verificar si esta podría resolver el problema, lo cual nos llevó a ejecutar la aplicación y funcionó perfectamente, ya que transmitía las imágenes al celular sin ningún problema y capturaba fotos y videos que guardaba en la memoria interna del celular con opciones de resolución de imágenes.

Ahora el proceso endoscópico es realizado mediante el endoscopio y el dispositivo móvil, esto con la ayuda de las siguientes tres aplicaciones:

- Dashcam

- Aplicación para visualizar las imágenes transmitidas del endoscopio al celular y capturar imágenes en formato.jpg y videos en.mp4

- Video player for Android

- Aplicación que permitirá ver los videos guardados por Dashcam ya que el reproductor nativo de Android no soporta los videos grabados por la aplicación

- Mis Archivos (Aplicación nativa de Android)

- Las imágenes capturadas por Dashcam no se muestran directamente en la galería del celular hasta que este sea reiniciado y la galería sea actualizada. Sin embargo se puede acceder a las imágenes mediante esta aplicación dirigiéndonos a la ruta DCIM/Dashcam donde se encuentran las imágenes y videos que sean capturados

Es necesario indicar que Dashcam tiene sus limitaciones: 1) muchos dispositivos no dan soporte para UsbHost que permite poder conectar dispositivos USB externos al móvil y 2) las versiones de Android 4.4.2 necesitan tener permisos de súper usuario y con versiones 4.3 es posible que también los necesite, véase la tabla 2.

El proceso se hace conectando el endoscopio al cable OTG y este a su vez se conecta al dispositivo móvil, ya conectado el endoscopio se ejecuta la aplicación Dashcam y si su dispositivo cumple con las características, en pantalla se mostrará lo que el endoscopio este capturando con su cámara. Hecho esto es posible que el doctor realice cualquier operación quirúrgica que necesite el paciente. A pesar de ello, se trata de una solución temporal, ya que el código fuente de la aplicación Dashcam se tiene que modificar. 


\begin{tabular}{|c|c|c|c|c|}
\hline Modelo & $\begin{array}{l}\text { Versión de } \\
\text { Android }\end{array}$ & $\begin{array}{l}\text { Súper Usuario (device } \\
\text { rooted) }\end{array}$ & $\begin{array}{l}\text { Soporta } \\
\text { UsbHost }\end{array}$ & Funcionó \\
\hline $\begin{array}{l}\text { Samsung Galaxy } \\
\text { S4 }\end{array}$ & 4.2 .2 & $\times$ & $\checkmark$ & $\checkmark$ \\
\hline $\begin{array}{l}\text { Samsung Galaxy } \\
\text { S4 }\end{array}$ & 4.4 .2 & $x$ & $\checkmark$ & $\times$ \\
\hline $\begin{array}{l}\text { Samsung Galaxy } \\
\text { S4 }\end{array}$ & 4.4 .2 & $\checkmark$ & $\checkmark$ & $\checkmark$ \\
\hline $\begin{array}{l}\text { Samsung Galaxy } \\
\text { Tab } 4\end{array}$ & 4.4 .2 & $\times$ & $\checkmark$ & $\times$ \\
\hline LG l9 & 4.1 .2 & $x$ & $\checkmark$ & $x$ \\
\hline LG Hub & 2.3 .4 & $\times$ & $x$ & $\times$ \\
\hline Sony Xperia N1 & 4.3 & $\times$ & $x$ & $\times$ \\
\hline Alcatel 6030 & 4.0 .4 & $\times$ & $\checkmark$ & $\times$ \\
\hline
\end{tabular}

Tabla 2 - Dispositivos de prueba Dashcam ${ }^{1}$.

El siguiente paso por realizar son las pruebas con la aplicación en su estado original en situaciones reales, es decir, intubar y realizar procedimientos quirúrgicos en pacientes reales dentro de un quirófano para así conocer si es factible llevar a cabo la modificación de la aplicación y obtener una acorde a las necesidades del doctor.

\section{Análisis de Resultados y Beneficios}

Existen diversos procedimientos quirúrgicos que se pueden realizar con el uso de esta aplicación tales como la tiroidectomía que básicamente es cualquier intervención sobre la glándula tiroides en la que se extirpe toda o una parte de ella (Palés Castro Marisol, 2000) como se muestra la figura 1.
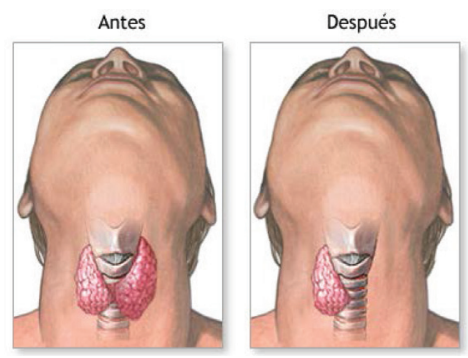

Figura 1 - Extirpación de una parte de la tiroides

La amigdalectomía que es la extirpación de las amígdalas palatina (Palés Castro Marisol, 2000), véase figura 2.

${ }^{1}$ La tabla 2 hace referencia a los dispositivos en los cuales se probó la aplicación Dashcam. La columna Súper Usuario indica si el dispositivo esta rooteado, es decir, si tiene permisos de súper usuario y la columna Soporta UsbHost indica si el dispositivo soporta esta característica. 


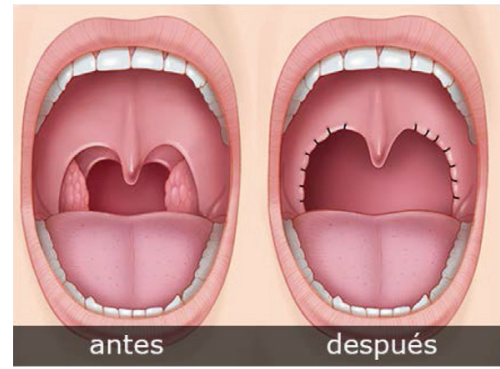

Figura 2 - Extirpación de las amígdalas

La apendicectomía es la extirpación quirúrgica del apéndice cecal (Palés Castro Marisol, 2000). Para este procedimiento te hace una pequeña incisión en la parte de del abdomen inferior izquierda (véase figura 3) para después realizar la extirpación véase figura 4.

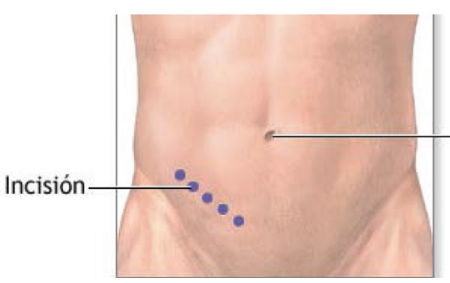

Figura 3 - Incisión para retirar el apéndice
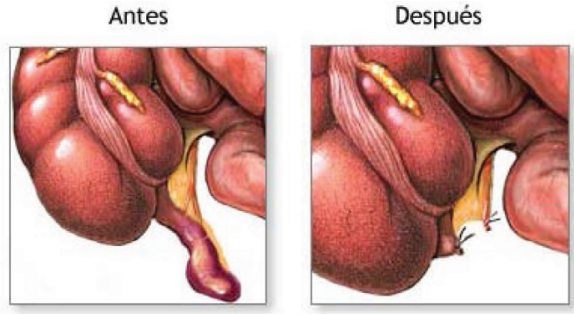

Figura 4: Extirpación de apéndice

Colecistectomía laparoscópica: Extirpación quirúrgica de la vesícula biliar mediante técnica laparoscópica (Palés Castro Marisol, 2000), como se muestra en la figura 5.

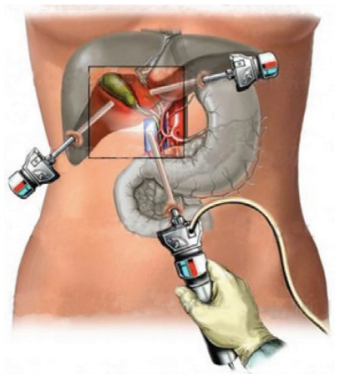

Figura 5 - Extirpación de vesícula biliar

El estrabismo que es la desviación espontánea de los ejes oculares, la mastectomía extirpación total de la glándula mamaria o de una parte de la misma, septumplastia, cirugía que se realiza para corregir las deformidades o desviaciones del tabique nasal, también llamado septum nasal y muchos otros procedimientos (Palés Castro Marisol, 2000). 
Al contar con una aplicación funcional, se probó en un ambiente real con el doctor Guillermo Velázquez, quien realizó 30 pruebas de 14 diferentes procedimientos quirúrgicos dentro de los cuales vienen los anteriormente dichos, en pacientes del Hospital General de Zacatecas donde solo se presentó una complicación, que a mitad de uno de los procedimientos entro una llamada al dispositivo, en el cual se visualizaban las imágenes, este se resolvió activando el modo avión durante los procedimientos posteriores a este, véase la tabla 3. Cabe mencionar que cuando se tiene un cero en la columna de minutos grabados y numero de fotografías es porque el procedimiento quirurgico se realizo sin ninguna necesidad de grabar o guardar archivos. Todas las pruebas fueron realizadas en un dispositivo Samsung $\mathrm{S}_{4}$.

\begin{tabular}{|c|c|c|c|c|}
\hline & Procedimiento quirúrgico & $\begin{array}{l}\text { Minutos } \\
\text { grabados }\end{array}$ & $\begin{array}{l}\text { Numero de } \\
\text { Fotografías }\end{array}$ & Complicación \\
\hline 1 & TIROIDECTOMIA & $\mathrm{O}$ & $\mathrm{O}$ & $\mathrm{NO}$ \\
\hline 2 & AMIGDALECTOMIA & $\mathrm{O}$ & 1 & $\mathrm{NO}$ \\
\hline 3 & AMIGDALECTOMIA & 2 & $\mathrm{O}$ & $\mathrm{NO}$ \\
\hline 4 & $\begin{array}{l}\text { LAPAROTOMIA } \\
\text { EXPLORADORA }\end{array}$ & o & O & $\mathrm{NO}$ \\
\hline 5 & $\begin{array}{l}\text { TRAUMATISMO } \\
\text { CRANEOENCEFALICO }\end{array}$ & $\mathrm{O}$ & $\mathrm{O}$ & SI \\
\hline 6 & SEPTUMPLASTIA & 1 & 1 & NO \\
\hline 7 & SEPTUMPLASTIA & o & $\mathrm{O}$ & NO \\
\hline 8 & AMIGDALECTOMIA & o & $\mathrm{O}$ & $\mathrm{NO}$ \\
\hline 9 & AGENESIA DE COANAS & 1 & o & NO \\
\hline 10 & SEPTUMPLASTIA & 1 & $\mathrm{O}$ & $\mathrm{NO}$ \\
\hline 11 & $\begin{array}{l}\text { LAPAROTOMIA } \\
\text { EXPLORADORA }\end{array}$ & $\mathrm{o}$ & $\mathrm{O}$ & $\mathrm{NO}$ \\
\hline 12 & TIRIODECTOMIA & o & 0 & NO \\
\hline 13 & FRACTURA DE MANDIBULA & o & o & NO \\
\hline 14 & TUMORACION DE LENGUA & o & $\mathrm{O}$ & $\mathrm{NO}$ \\
\hline 15 & $\begin{array}{l}\text { TRAUMATISMO } \\
\text { CRANEOENCEFALICO }\end{array}$ & o & o & NO \\
\hline 16 & SEPTUMPLASTIA & o & o & NO \\
\hline 17 & AMIGDALECTOMIA & $\mathrm{o}$ & $\mathrm{o}$ & NO \\
\hline 18 & ESTRABISMO & 0 & 0 & NO \\
\hline 19 & ESTRABISMO & o & $\mathrm{O}$ & NO \\
\hline 20 & QUEMADURA EN CARA & o & $\mathrm{O}$ & NO \\
\hline 21 & AMIGDALECTOMIA & $\mathrm{O}$ & $\mathrm{O}$ & NO \\
\hline 22 & $\begin{array}{l}\text { LAPAROTOMIA } \\
\text { EXPLORADORA }\end{array}$ & O & O & $\mathrm{NO}$ \\
\hline 23 & SEPTUMPLASTIA & o & 0 & $\mathrm{NO}$ \\
\hline
\end{tabular}




\begin{tabular}{llccc}
\hline Procedimiento quirúrgico & $\begin{array}{c}\text { Minutos } \\
\text { grabados }\end{array}$ & $\begin{array}{c}\text { Numero de } \\
\text { Fotografías }\end{array}$ & Complicación \\
\hline 24 & APENDICECTOMIA & o & o & NO \\
\hline 25 & $\begin{array}{l}\text { COLECISTECTOMIA } \\
\text { LAPAROSCOPICA }\end{array}$ & o & 0 & NO \\
\hline 26 & $\begin{array}{l}\text { COLECISTECTOMIA } \\
\text { LAPAROSCOPICA }\end{array}$ & o & 0 & NO \\
\hline 27 & $\begin{array}{l}\text { RESECCION DE TUMOR } \\
\text { DE RINNON }\end{array}$ & o & 0 & NO \\
\hline 28 & MASTECTOMIA & o & o & NO \\
\hline 29 & MASTECTOMIA & o & o & NO \\
\hline 30 & TIROIDECTOMIA & o & o & NO \\
\hline
\end{tabular}

Tabla 3 - Bitácora de pruebas realizadas en quirófano.

Todo esto con ayuda de Dashcam y el endoscopio que en todas y cada una de las pruebas fue introducido ya sea por la cavidad bucal, alguna incisión que se haya hecho u orificio natural dependiendo del procedimiento quirúrgico que se haya practicado, ayudando así al doctor a tener una mejor visión del lugar.

Los sistemas endoscópicos actuales tienen muchas características muy útiles tales como: calendario y monitoreo de pacientes, generación de reportes, interface de patología, registro de instrumentos su uso y mantenimiento del mismo, inventario de fármacos y suministros, investigación y búsqueda clínica, entre otras (Atreja, Rizk, \& Gurland, 2010). Aunque Dashcam no provea muchas de estas características, si nos da la funcionalidad fundamental que es visualizar lo que el endoscopio muestra del interior humano, agregándole que puede capturar fotos y videos; cabe mencionar que la calidad de la imagen es muy buena, tal como puede verse en la Figura 6 y 7.

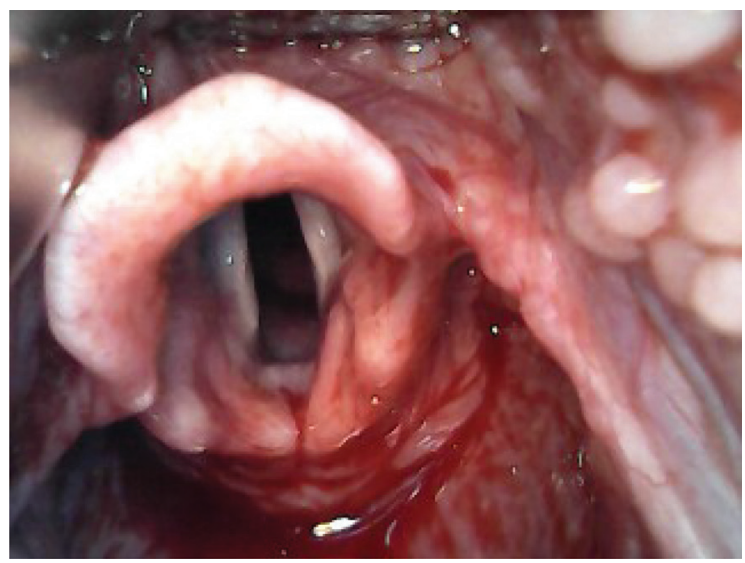

Figura 6 - Fotografía de la epiglotis tomada durante una de las pruebas realizadas por el Doctor Guillermo Velázquez 


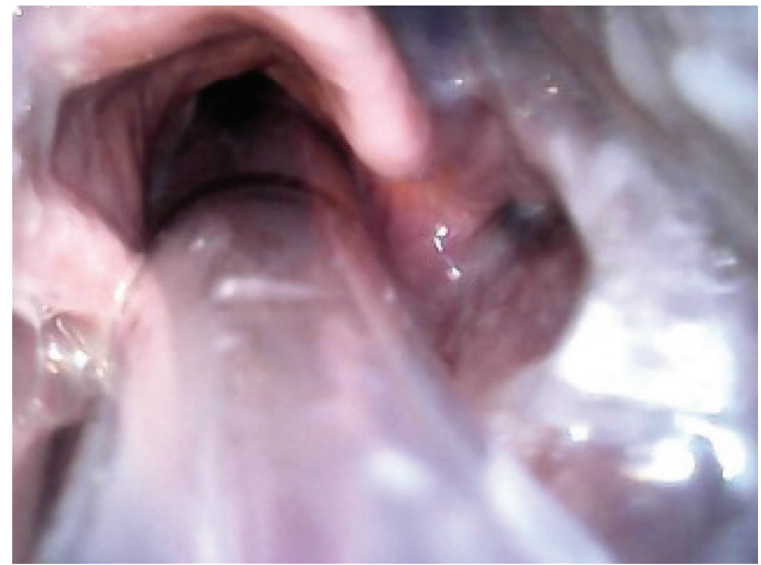

Figura 7 - Intubación del paciente

Ahora bien, las funciones que el endoscopio provee para PC no son muy diferentes de las que nos da la aplicación Dashcam, ya que en la PC nos permite capturar fotografías y videos y configurar el lugar donde se guardaran al igual que en la aplicación, la única diferencia que se tiene es que en el software de PC se tiene una especie de temporizador el cual restringe el tiempo de duración de los videos. Por consiguiente se puede asegurar que en cuanto a procesos, calidad de imagen, conectividad y funciones son practicante los mismos; donde se ve la diferencia es en la agilidad, movilidad y robustez de los aparatos ya que un dispositivo móvil es más compacto y hace que su uso sea más sencillo y rápido de utilizar.

Se consiguió mejorar el procedimiento endoscópico, ya que al cambiar la PC por un dispositivo móvil, las herramientas necesarias para realizarlo son más prácticas, ahora solo será de carácter obligatorio llevar el endoscopio y el cable OTG, ya que el dispositivo móvil en la actualidad es muy difícil que se olvide por accidente en algún lugar y aun cuando pase esto como se mencionó en el apartado anterior más de 16.235 millones de personas en México cuentan con un Smartphone, lo cual hace que tu herramienta de trabajo la puedas encontrar casi en cualquier lugar que se esté ya que una endoscopia "se pude realizar en la oficina del doctor, algún centro de cirugía ambulatoria o en un hospital" (Mayo Clinic Staff, 2015).

Después de la realización de las pruebas y sabiendo que la aplicación Dashcam era de utilidad y que mejoraba el proceso endoscópico, se procedió a obtener el código fuente de la aplicación con ingeniería inversa para así realizar modificaciones al mismo y obtener una aplicación acorde a las necesidades del doctor. Se podrían quitar características innecesarias para la endoscopia, tales como: remover anuncios de la aplicación, quitar los tamaños de resoluciones del menú ya que el endoscopio tiene como predeterminada 640x480, quitar los mensajes de depuración en consola y dejar por default en modo pantalla completa.

Actualmente se encuentra en proceso de adaptación, ya que por medio de la herramienta apktojava se realizóla ingeniería inversa de la aplicación pero venía con código basura, esto a causa de la herramienta ProGuard, la cual encoge, optimiza, y esconde código renombrando 
clases, campos, métodos con nombres no reconocibles semánticamente; dejando como resultado un.apk más pequeña en tamaño y difícil de entender (Developers, 2015).

Sin embargo se pueden percibir fragmentos de código en los cuales describe la funcionalidad de cómo es que trabaja en conjunto con el endoscopio y es entonces de aquí de donde se partiría para adecuar la aplicación a las necesidades del doctor. Las Figuras 8 y 9 muestran cómo es que la Dashcam inicia la cámara y la detiene. Las Figura 10 y 11 muestran el código con el cual realiza las acciones de la captura de fotos y video.

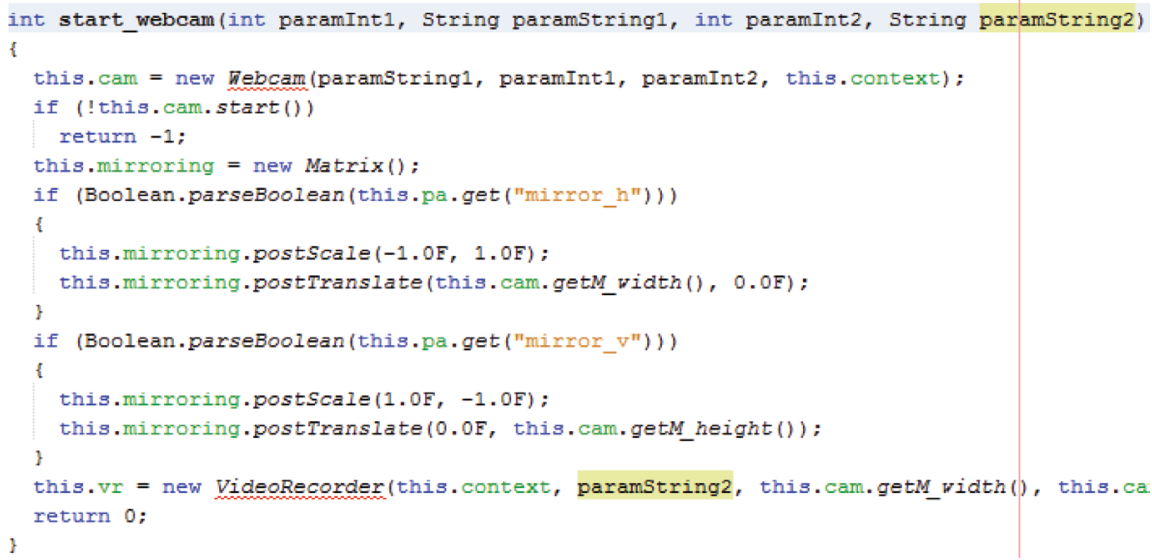

Figura 8 - Método de la clase CameraView para encendido.

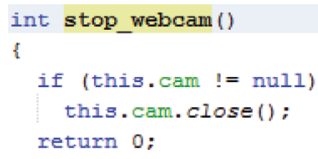

Figura 9 - Método de la clase CameraView para apagado.

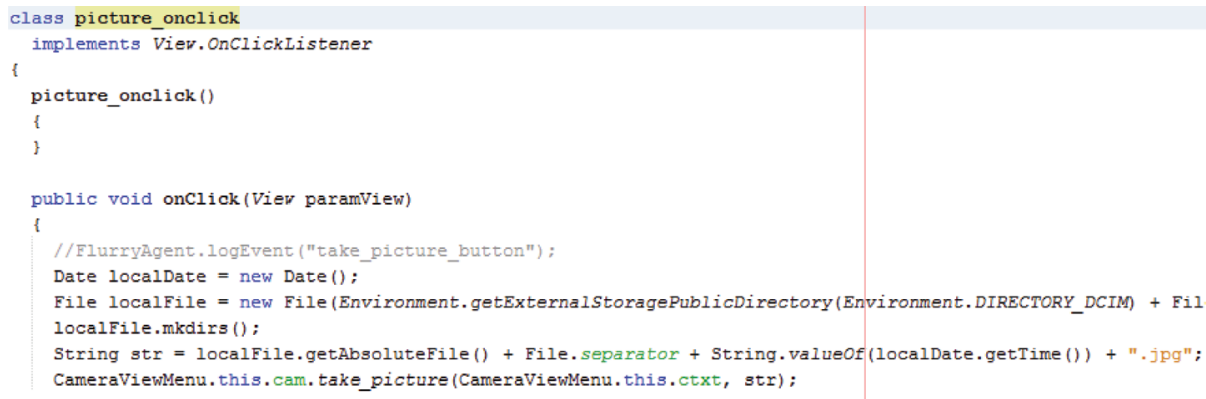

Figura 10 - Clase interna de CameraViewMenu para capturar fotos, donde en el método onClick de la clase va el código que indica el lugar donde se guardara la fotografía y viene la orden especifica de take_picture para tomarla. 


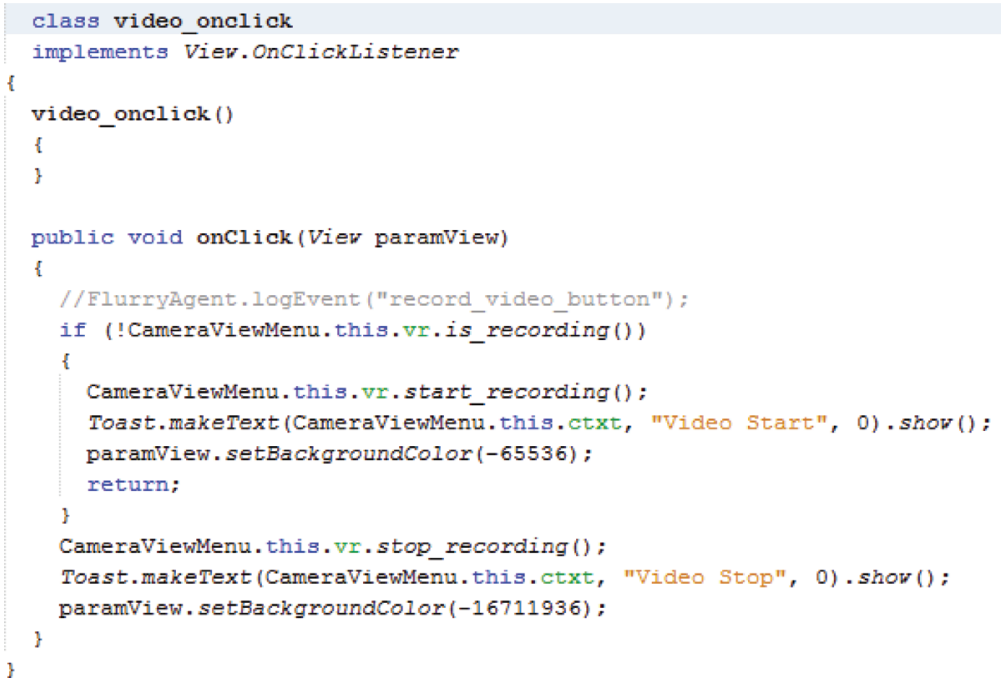

Figura 11 - Clase interna de CameraViewMenu para capturar videos, donde método onClick verifica si está grabando y en caso de que no inicializa con start_recording() y para detenerlo es el stop_recording().

\section{Conclusiones y Recomendaciones}

Como se mencionó anteriormente al realizar la ingeniería inversa de la aplicación Dashcam se obtuvo código realmente útil pero con muchos errores. Cabe destacar que Dashcam cuenta con 1,122 clases de java en las cuales la mayoría de ellas contienen más 100 líneas de código en promedio, es decir, más de 11,220 líneas aproximadamente que requieren ser analizadas para conocer en su totalidad el funcionamiento de la aplicación, añadiendo que existen alrededor de 6,559 errores que necesitan ser corregidos, pero aun así se trata de una solución funcional contribuyendo en diagnósticos, toma de decisiones y procesos quirúrgicos vitales para personas con problemas de la salud porque cuenta con las funcionalidades de visualización de imágenes transmitidas por el endoscopio, la captura de imágenes y la grabación de video.

Ahora que ya sabemos que la aplicación fue de gran utilidad para el doctor como se mostró en la bitácora de pruebas realizadas en quirófano (Tabla 3), es conveniente continuar con la investigación y tratar de concretar la idea para así obtener un producto compatible con más dispositivos móviles, sin la necesidad de que los celulares tengan root (acceso a muchas características del Sistema Operativo del celular que vienen bloqueadas desde fábrica), ayudando a la medicina y otras áreas donde pueda ser utilizada. Ya con la aplicación Dashcam funcionando y con la certeza de que cumple con las necesidades endoscópicas es necesario crear esa API externa inexistente a partir de la ingeniería inversa que permita controlar cámaras web y dar instrucciones de cómo hacerlo.

Una vez conseguido esto, otra modificación sería con el propósito de obtener una aplicación acorde a las necesidades del proceso endoscópico, es decir remover características que son innecesarias para la endoscopia como lo son: las distintas resoluciones que vienen y 
dejar por defecto en 640x480 misma que utiliza el endoscopio, los anuncios publicitarios de la misma y los formatos de los videos e imágenes.

Lo conveniente sería dejar una aplicación libre de errores y publicidad, donde los formatos estén establecidos por defecto como jpg para imágenes y mp4, resolución por defecto de 640x480 y permitir visualizar las imágenes y videos capturados de manera inmediata sin necesidad de reiniciar el dispositivo.

\section{Referencias}

Arango, J. E., Mazo, J. C., \& Palacio, A. P. (2013). Sistema para Rehabilitación del Síndrome del Miembro Fantasma utilizando Interfaz Cerebro-Computador y Realidad Aumentada. Revista Ibérica de Sistemas Y Tecnologías de La Información n.11, 93-106. http://doi.org/http://dx.doi.org/10.4304/risti.11.93-106.

Atreja, A., Rizk, M., \& Gurland, B. (2010). A primer on endoscopic electronic medical records. Clinics in Colon and Rectal Surgery, 23(1), 5-9. http://doi. org/10.1055/s-0030-1247850.

Christopher Peplin. (2011). openxc/android-webcam. Retrieved from https://github. com/openxc/android-webcam.

Developers, A. (2015). ProGuard | Android Developers. Retrieved March 21, 2015, from http://developer.android.com/tools/help/proguard.html

Endoscopes: Upper Gastrointestinal (GI), Gastroscopy, EG-2990i. (2014). Retrieved April 5, 2014, from http://us.pentaxmedical.com/en/products/endoscopes/uppergastrointestinale/gastroscopes/EG-2990i.aspx.

Freixo, J., \& Rocha, Á. (2014). Information Architecture to Support Quality Management in Hospital Units. Revista Ibérica de Sistemas Y Tecnologías de La Información No.11, 1-15. http://doi.org/http://dx.doi.org/10.17013/risti.14.1-15.

IAB Mexico, M. B. (2012). IAB México presenta el primer Estudio de Usos y Hábitos de Dispositivos Móviles en nuestro país | IAB MEXICO. Retrieved June 18, 2015, from http://www.iabmexico.com/usos_habitos_mobile.

Mayo Clinic Staff. (2015). Upper endoscopy - Mayo Clinic. Retrieved September 3, 2015, from http://www.mayoclinic.org/tests-procedures/endoscopy/basics/definition/ prc-20020363? $\mathrm{p}=1$

Olympus América de México S.A. de C.V. (2014). Retrieved April 5, 2014, from http://www.olympusmexico.com.mx/spanish/msg/msg_product_detail_esp. asp?d $=1 \& \mathrm{~s}=4 \& \mathrm{c}=16 \& \mathrm{~g}=2092$

Palés Castro Marisol, J. I. A. (2000). Diccionario Medico Espasa. (C. V. Rodríguez, Ed.) (200oth ed.). Navarra, España.

Ventola, C. L. (2014). Mobile devices and apps for health care professionals: uses and benefits. P \& T: A Peer-Reviewed Journal for Formulary Management, 39(5), 356-64. Retrieved from http://www.pubmedcentral.nih.gov/articlerender. fcgi ?artid $=4029126 \&$ tool $=$ pmcentrez\&rendertype $=$ abstract 